\title{
Blinded by Experience: Prior Experience, Negative News and Belief Updating
}

\section{Citation}

Staats, Bradley R., Diwas S. KC, and Francesca Gino. "Blinded by Experience: Prior Experience, Negative News and Belief Updating." Harvard Business School Working Paper, No. 16-015, August 2015.

\section{Permanent link}

http://nrs.harvard.edu/urn-3:HUL.InstRepos:19052348

\section{Terms of Use}

This article was downloaded from Harvard University's DASH repository, and is made available under the terms and conditions applicable to Open Access Policy Articles, as set forth at http:// nrs.harvard.edu/urn-3:HUL.InstRepos:dash.current.terms-of-use\#OAP

\section{Share Your Story}

The Harvard community has made this article openly available.

Please share how this access benefits you. Submit a story.

Accessibility 


\section{Blinded by Experience: Prior Experience, Negative News and Belief Updating}

Bradley R. Staats

Diwas S. KC

Francesca Gino

Working Paper 16-015 


\title{
Blinded by Experience: Prior Experience, Negative News and Belief Updating
}

\author{
Bradley R. Staats
}

University of North Carolina

Diwas S. KC

Emory University

Francesca Gino

Harvard Business School

Working Paper 16-015 


\title{
Blinded by Experience: \\ Prior Experience, Negative News and Belief Updating
}

\author{
Bradley R. Staats \\ University of North Carolina at Chapel Hill \\ Campus Box 3490, McColl Building \\ Chapel Hill, NC 27599-3490 \\ Tel: 919.962.7343 \\ bstaats@unc.edu
}

Diwas S. KC

Emory University

1300 Clifton Road

Atlanta, GA 30322

Tel: 404.727.1424

diwas.kc@emory.edu

\author{
Francesca Gino \\ Harvard Business School \\ Harvard University, Baker Library \\ Boston, MA 02163 \\ Tel: 617.495 .0875 \\ Fax: 617.496.4191 \\ fgino@hbs.edu
}

August 10, 2015

\section{Acknowledgments}

We thank Ryan Buell, Rachel Croson, Andrew Davis, Uri Simonsohn, and Tom Tan for insightful comments that helped us develop this work. Any errors are the responsibility of the authors.

The Pennsylvania Health Care Cost Containment Council (PHC4) is an independent state agency responsible for addressing the problem of escalating health costs, ensuring the quality of health care, and increasing access to health care for all citizens. While PHC4 has provided data for this study, PHC4 specifically disclaims responsibility for any analyses, interpretations, or conclusions. 


\begin{abstract}
Traditional models of operations management involve dynamic decision-making assuming optimal (Bayesian) updating. However, behavioral theory suggests that individuals exhibit bias in their beliefs and decisions. We conduct both a field study and two laboratory studies to examine the phenomena in the context of health. In particular, we examine how an individual's prior experiences and the experiences of those around them alter the operational decisions that the individual makes. We draw on an exogenous announcement of negative news by the Food and Drug Administration (FDA) and explore how this affects an operational decision - production tool choice - of interventional cardiologists deciding between two types of cardiac stents. Analyzing 147,000 choices over 6 years, we find that individuals do respond to negative news by using the focal production tool less often. However, we find that both individual's own experience and others' experience alter their responses in predictable ways. Moreover, although individual and other experience act as substitutes prior to negative news, the two types of experience act as complements following the negative announcement - leading to even greater use of the same production tool. Two controlled lab studies replicate our main findings and show that behavioral biases, not rational expectations, drive the effect. Our research contributes not only to operations management research, but also to the practice of healthcare and operations more generally.
\end{abstract}

Key Words: Behavioral Operations, Egocentric Bias, Experience, Healthcare Operations

\title{
1. Introduction
}

The field of operations management is fundamentally concerned with process improvement. From its roots in Scientific Management (Smiddy and Naum 1954; Gino and Pisano 2008) to the development and refinement of analytical models for making better decisions (Dantzig 1955; Wagner and Whitin 1958) and the empirical examination of processes for prescriptive enhancement (Clark 1989; Fisher and Ittner 1999) the field has a long tradition of identifying gaps in prior work and practice and filling them with new quantitative tools and theory. Although some situations are single period (e.g., newsvendor or a transactional contract) or multi-period but static (e.g., economic order quantity or $\mathrm{M} / \mathrm{M} / \mathrm{c}$ queues), increasingly both the models and the practice they represent are multi-period and dynamic. As such, decision makers observe the consequences of a particular action and then must use this information to determine their next action. Illustrative examples can be seen in a wide variety of contexts, including labor scheduling (Kesavan, Staats and Gilland 2014; Tan and Netessine 2014), production tool choice (Upton 1997; Ramdas et al. 2010), job shop scheduling (Fryer 1975), local capacity decisions (Campbell and Frei 2011), inventory ordering (van Donselaar et al. 2010), pricing (Phillips, Şimşek and Ryzin 2015), research and development investment (Chao, Kavadias and Gaimon 2009), and Bayesian models (Brown, Lu and Wolfson 1964) more generally. In these and other models, individuals are assumed to use Bayesian updating to generate their beliefs, which ultimately determine their next action.

However, recent work in behavioral operations, psychology and economics challenges the notion that individuals act rationally when updating their beliefs (Bendoly, Donohue and Schultz 2006; Gans, Knox and Croson 2007; Gino and Pisano 2008). This paper explores whether the belief updating process 
may be flawed in predictable ways when human decision makers are involved. The question is an important one since both theoretical and practical improvement models rest on a foundation of repetitive analysis and action cycles (Deming 1986; MacDuffie 1997). We examine how individuals respond to the revelation of negative news (news that their previous choices may have been incorrect or suboptimal) when making subsequent choices. A failure to update beliefs in response to negative news has been cited as a cause in mistakes that have led to billions of dollars in waste - such as rogue traders at investment banks, Motorola's Iridium satellite phone, or the ongoing operation of the Concorde supersonic jet. We focus on negative news because positive news is unlikely to lead to significant behavioral change - either as a result of having made the correct choice in the first place or because of the status quo bias. On the other hand, negative news, if sufficiently serious, should lead to a behavioral change.

Prior research in the domains of consumer choice (Cutler, Huckman and Landrum 2004; Sinaceur, Heath and Cole 2005; Zhao, Zhao and Helsen 2011), psychology (Camerer and Lovallo 1999; Yaniv 2004; Bonaccio and Dalal 2006), and operations management (Thirumalai and Sinha 2011; KC, Staats and Gino 2013; Shah, Ball and Netessine 2013) have explored how new information influences people's subsequent choices and outcomes. For example, Simonsohn (2011) finds that consumers not only respond to reviews when purchasing child car seats, but also update their beliefs and purchasing decisions when the information in the reviews is corrected following a mistake made by the reviewing organization. However, although this work establishes a baseline effect that individuals respond to negative news in their purchasing decisions at the population level, it has not been extended to the context of an operational decision maker.

More fundamentally, prior work has not considered how differences in experience may alter the belief-updating process after receiving negative news. Experience is an important variable to examine, as research in operations has focused a great deal on the benefits of experience, highlighting how increased experience may lead to improved performance due to improved knowledge (e.g., Lapré and Nembhard 2010; Staats and Gino 2012; Arlotto, Chick and Gans 2014). In particular, experience in a given domain provides greater knowledge with which to evaluate any negative news; however, it also introduces the possibility of biases, such as escalation of commitment (Sleesman et al. 2012) to prior decisions, which may lead to a failure to update one's beliefs correctly. Moreover, not only might one's own experience lead to different responses to negative news, but so too might the experiences of those surrounding a focal individual. Thus, in this paper we are the first to ask and answer: How do individual experience and the experience of others affect an individual's response to negative news?

A consistent challenge in understanding how individuals respond to external information and update their beliefs is that exposure often depends on an endogenous information search process that may be affected by the independent variables of interest. One approach is to identify exogenous shocks to 
create a causal identification strategy (e.g., Simonsohn 2011; Zhao et al. 2011), which secures external validity but typically limits one's ability to identify mechanisms. Another approach is to study the topic in the laboratory, which gains internal validity and information about a potential mechanism at the cost of external generalization. We follow both approaches by first examining data from the field using an exogenous shock to identify our effect causally. We then go to the controlled environment of laboratory studies to extend and conceptually replicate our findings, as well as to identify a potential mechanism escalation of commitment - driving the effect.

Our field study exploits a novel empirical setting: interventional cardiology and the selection of type of coronary stent (i.e., the production technology that cardiologists use to do their work). From the time of Frederick Taylor (1911) and his studies on choosing the right size shovel for the material being moved to modern-day decisions on the flexibility of operational equipment (Upton 1997; Goyal and Netessine 2011) or the use of frontline problem-solving-focused production processes (MacDuffie 1997; Shah and Ward 2003; Tucker 2007) production tool choices have been a key operational decision. Improvement in production tool choice requires individuals to acquire information and then update their beliefs over time. In the case of coronary stents, cardiologists place stents in constricted arteries in order to maintain proper blood flow.

In the early 2000s, a new stent known as a drug-eluting stent was released to the market. The primary difference between the drug-eluting stent and its predecessor, the bare metal stent, is that the drug-eluting stent would release a small amount of drug over time in order to prevent restenosis (closing of the artery). Given that reimbursement rates for the two types of devices were comparable, cardiologists were faced with the decision of which stent to use based primarily on the medical merits. In late 2006, after concerns arose that drug-eluting stents were being used in non-FDA approved situations (termed "off-label use") and that these situations might lead to a greater risk of blood clotting (thrombosis) and even patient fatality, the FDA convened an emergency advisory panel and issued a warning that there could be dangers in off-label use (Farb and Boam 2007). Over the next several months, the drug-eluting share of the stent market fell from over $90 \%$ to around 60\% (Naidu 2010). Using detailed data from before and after this exogenous shock we are able to examine our research questions. Next, we turn to the laboratory to examine whether experience leads people to be less responsive to negative news about a past decision they invested in. By using laboratory studies we are able to gain internal validity, albeit without the external validity that the field study provides. With our lab study we seek not only to replicate conceptually both the effects of individual experience and others' experience on the belief updating process, but also show that the effect is driven by bias, not rational expectations.

Our archival and laboratory studies reveal four findings from the data. First, on average, after negative news, individuals do update their beliefs; for example, cardiologists are $37 \%$ less likely to use 
drug-eluting stents after the FDA's announcement. Second, in both the field and the lab, we find that individuals with more experience are less likely to respond to this negative news by changing their decision as compared to individuals with less experience. Third, our results show that individuals respond to those around them, as others' experience is related to an individual being more likely to make the same decision and not deviate from a prior belief. Finally, we consider the interactive effects of individual and others' experience. In particular, although in steady state we would expect these two types of experience to be substitutive, since they, at least in part, contain duplicative information (Schwab 2007; Clark, Huckman and Staats 2013), we explore whether, after negative news, the combination of cognitive and group effects might lead to a complementary effect. We find that although individual and other experience are substitutes prior to the negative news, after the emergency advisory panel's announcement the two types of experience switch to a complementary relationship whereby they interact to make an individual more likely to choose a drug-eluting stent.

Our paper makes several contributions to operations theory and practice. First we show that individuals do update their beliefs in response to negative news in multi-period, dynamic settings. This finding extends what is known in consumer choice to a new domain. Moreover, there is value in documenting the effect size (Cachon 2012) as our field setting and exogenous shock permit us to estimate precisely the relationship between negative news and subsequent choice. Second, we find that individual experience plays a large role in predicting how individuals update their beliefs in response to negative news. In particular, although experience often can prove valuable due to the increased knowledge it brings, our findings show that experience can also prove maladaptive in the belief-updating process. Our results are consistent with a story of systematic bias, and particularly escalation of commitment, which leads individuals to self-justify their past decisions and thus respond significantly less than desired to negative news that suggest those decisions were poor ones. Third, our results show the important role of others' experience in how individuals respond to information. Other individuals provide not only a source of additional knowledge but also create the possibility of social pressure. We find that individuals respond strongly to others' experiences in ways consistent with a social-pressure argument. Fourth, the significant interaction term between individuals' and others' experiences shows that these effects are not independent. Rather, in steady-state operations, the two types of experience substitute one another, but after the negative news, the complementary response suggests that when a need for self-justification meets social pressure, then trouble may ensue. Finally, our findings offer important guidance for both medical professionals and operations managers more generally as they think about how to help individuals update their beliefs in an uncertain world. 


\section{Updating Beliefs in Response to Negative News}

Prior research in operations has typically focused on operational predictors of negative news, or how negative news affects subsequent operational or financial performance. Research in this tradition can be seen in the examination of product recalls (Thirumalai and Sinha 2011; Shah et al. 2013), supply chain disruptions (Hendricks and Singhal 2005; Schmidt and Raman 2015), or operational failures (Haunschild and Rhee 2004; KC et al. 2013). In this paper, we consider how individuals update their beliefs in response to negative news. There are a number of different paradigms that can be used to consider how people update beliefs and make decisions. Perhaps the most basic, albeit one that has shown significant theoretical and empirical power, is that of expected utility (Simon 1959; Good 1962; Von Neumann and Morgenstern 2007). In an expected utility framework, individuals are seeking to maximize, or at least "satisfice," along the usefulness of an outcome. That usefulness is often captured through economic value, but it can also incorporate other factors of interest to the decision maker. Prior to receiving negative news, an individual assesses the expected utility from different choices and selects the one with the maximum utility. For example, a doctor would consider available information about various production technologies and their potential fit with a given patient and then select the one that is expected to provide the best outcome. Similarly, when making local capacity decisions (Campbell and Frei 2011), a manager would weigh the information available at the time and then choose where to open a new branch. After receiving negative news, individuals should reassess expected utility by incorporating additional information. Assuming that the negative news does not affect all of the choice set equally-for example, in our field setting the warning referred to drug-eluting stents, not to the alternative bare metal stentsthen a decision maker would update her calculation of expected utility and potentially change at least some of her decisions. Prior studies have used this framework to show that consumers do in fact respond to new knowledge, for example, in the form of an expert opinion on restaurant hygiene (Jin and Leslie 2003), doctor quality (Cutler et al. 2004), university quality (Pope 2009), and car seat safety (Simonsohn 2011).

Research in behavioral decision making suggests that individuals are not always rational maximizers (Tversky and Kahneman 1974), as confirmed by research examining how individuals respond to advice from others (Bonaccio and Dalal 2006). This stream of lab-based research has generated a number of interesting findings. For example, individuals discount bad advice more than they discount good advice (Yaniv and Kleinberger 2000), and they value advice more when they pay for it, holding the quality of advice constant (Gino 2008). One of the most consistent findings in this line of work is that individuals appear to exhibit an egocentric bias, such that they discount advice from others more than they should (Yaniv 2004; Bonaccio and Dalal 2006). Given that this research has been done in the lab, it is possible to identify how advice contributes to a given task design and therefore show that individuals 
would benefit economically from following advice more closely.

Several reasons have been given as to why individuals may show a bias for their own prior opinion (Bonaccio and Dalal 2006). One explanation is that since individuals have access to the logic that led to their own conclusion, they exhibit a preference for that conclusion, as compared to advice from others (Yaniv and Kleinberger 2000; Yaniv 2004). An alternative explanation is that individuals anchor on their prior viewpoint and then, when new information is presented, insufficiently adjust to it (Harvey and Fischer 1997). A third explanation is that individuals may simply prefer their own viewpoint, believing it is more accurate than the information presented by others (Krueger 2003).

Despite these behavioral reasons suggesting that people do not follow advice as much as they should, these studies more often than not do show that individuals still respond some to information received by others, even when it differs from their initial opinion. Therefore, our first, baseline hypothesis posits that negative news will have an effect on production technology choice:

HYPOTHESIS 1: $\quad$ After receiving negative news about an operational decision, individuals will be less likely to choose the same prior decision.

\subsection{Negative News and Individual Experience}

Although we expect that, on average, individuals will respond to negative news by updating their beliefs and then altering their choice, an important question is how an individual's prior experience in a given domain affects that choice. There are valid theoretical reasons suggesting that more experienced individuals might be more or less likely to respond more strongly to negative news. Next we consider the possible effects.

First, returning to the expected utility framework, by definition, a more experienced individual will have more knowledge with which to evaluate negative information. It is not clear, however, whether that additional evaluation will make an individual more or less likely to change his decision. There may be times when greater knowledge allows someone to understand that negative news is not as bad it first appears. For example, when someone learns that his probability of experiencing a defect with a production technology has increased by an order of magnitude, he is likely to become quite concerned. However, an expert who realizes that the base rate is $0.00001 \%$ will still respond to the new information but appreciate that it remains an unlikely outcome. Alternatively, it is possible that greater knowledge could lead an experienced individual to take negative news even more seriously than a less experienced individual. For example, in casting metal parts, tiny bubbles known as blowholes can occur as defects within the casting. An inexperienced person might assume that such a small defect would not be particularly problematic, while an experienced individual would understand that the defect may require the part to be scrapped. 
Regardless of this positive or negative response, a less experienced individual is likely to have a greater standard deviation around a possible outcome after receiving negative news, since she should have less certainty about the underlying relationships. Assuming that the person is even somewhat risk averse, a higher degree of uncertainty is associated with a lower level of utility. Specifically, for an individual with a Von Neumann Morgenstern utility function (Simon 1959; Good 1962; Von Neumann and Morgenstern 2007), the reduction in utility corresponding to the risk premium is higher with a greater uncertainty in possible outcomes. Therefore, an individual with lower utility due to limited experience with the given domain may be more inclined to switch to an alternative choice as compared to an individual with a greater degree of experience. In other words, we expect a stronger reaction to the negative news for the less experienced individual as compared to the more experienced individual. Overall, the exact type of news affects which direction the expected utility model would predict, in terms of response, although it seems possible that, more often than not, an experienced person would respond in a less extreme manner than would a less experienced individual.

Turning to behavioral effects on experience, the arguments point more strongly in the direction that experienced individuals may discount negative news more than less experienced individuals will. The question of how individuals process information has been a key area of psychological study. Prior work highlights that an individuals' prior experiences strongly affect their understanding of the world. When people receive negative news, they are confronted with two different cognitions - one from their prior understanding of the world, and a second that is based on the new information. The presence of these two different cognitions creates a state of cognitive dissonance that individuals then try to resolve (Festinger 1957). Self-justification theory posits that individuals often try to resolve this dissonance by rationalizing that their prior view of the world was correct (Sleesman et al. 2012). "Like a totalitarian government," writes Krueger (2003), "the ego has been said to shape perception in such a way that it protects a sense of its own good will, its central place in the social world and its control over relevant outcomes (p. 585)."

Moreover, work on the concept of escalation of commitment finds that not only do people find ways to self-justify their prior choices but that they may increase their commitment to a failing course of action (Staw 1981; Bazerman, Giuliano and Appelman 1984; Sleesman et al. 2012). Experienced individuals may choose to either ignore the negative information that they receive and/or believe they can overcome it such that they inadequately adjust to new information (Garland, Sandefur and Rogers 1990; Judge, Erez and Bono 1998; Tost, Gino and Larrick 2014). Perhaps most insidiously of all, these selfjustification biases often occur implicitly; people do not realize they are engaging in them (Krueger 2003).

Despite the theory and empirical work suggesting that more experienced individuals may be less likely to respond to negative information, there is some evidence to the contrary. In a set of lab 
experiments, Harvey and Fischer (1997) found that individuals who were given experience with a task were more likely to follow advice for important rather than less important judgments. Jeffrey (1992) found that more experienced auditors were less likely to engage in escalation of commitment than their less experienced counterparts. However, subsequent work suggests that experience influences how people view "importance" when they are outside of the lab in native contexts (Tost, Gino and Larrick 2012).

Ultimately, the answer to this question is an empirical one, but we think it likely that more experience will, on average, increase the odds of continuing with a present choice as compared to less experience. Individuals with more experience will not only have more information with which to analyze the news received, but self-justification biases are likely to lead these individuals to discount the negative news. Given the prior theorizing based on expected utility and self-justification logic, we hypothesize:

\section{HYPOTHESIS 2: $\quad$ After receiving negative news about an operational decision, individuals with} more experience will be more likely to choose the same prior decision than individuals with less experience.

\subsection{Negative News and Others’ Experience}

We next consider how others' experiences may affect how individuals update their beliefs in response to negative news. Using the same approach as we did for an individual's experience, we consider both an expected utility viewpoint and potential behavioral factors. First, the expected utility model works much as it did in the case above. When others have experience with an operational decision then a focal individual can benefit from her knowledge to understand any negative news that occurs. The idea of learning from others is well established in the literature on learning in organizations (Reagans, Argote and Brooks 2005; KC et al. 2013). Although others' experience provides a reservoir of knowledge as in the prior section, that knowledge could lead to more or less of a change in the use of a production technology, as compared to individuals without such access, depending on the contextual details. However, again, having access to others' knowledge should, on average, reduce the uncertainty that individuals face. This, in turn, should be associated with a higher expected utility and consequently a greater likelihood of continuing to use the production technology.

While the expected utility argument is again somewhat equivocal, the behavioral argument is much less so. A long line of research shows how strongly individuals respond to the experiences and opinions of others. For example, marketing research shows that word of mouth has a strong effect on consumer choice (Godes and Mayzlin 2004; Chevalier and Mayzlin 2006). More generally, individuals often respond to pressure from groups. Research finds that individuals will change their own opinion to match that of others in the group even if there is no explicit requirement for such unanimity (Janis 1982; Whyte 1993). This research has typically occurred in a context of group decision making, but it seems likely that the same logic would apply to individual decision making in the presence of related others 
making decisions, as individuals working together would have the opportunity to exert pressures on each other. Another reason to suspect that others' experiences may prove important comes from research showing that when there is more uncertainty, a group is more likely to conform (Asch 1965). Together, this suggests that individuals' responses to negative news are likely affected by the experience of the peers who surround them. Others with more experience are likely to either intentionally or subconsciously influence the decision of those around them. As a result, we hypothesize:

HYPOTHESIS 3: $\quad$ After receiving negative news about an operational decision, individuals who are around others with more experience will be more likely to make the same decision as those around them than individuals around others with less experience.

\subsection{Individual and Others' Experience: Complements or Substitutes?}

Finally, we consider the joint role that individual and other experience may have on an individual's updating of beliefs. We can consider the effect in steady state as well as after negative news is received. In steady state the two are likely to be substitutive. Individuals gain knowledge from their own experience with an operational decision and they have the ability to access knowledge when others around them make an operational decision. This question has been examined previously in literature on learning (Schwab 2007). For example, Clark, Huckman, and Staats (2013) find that individual and organizational customer experience serve as substitutes, with respect to learning from customer experience in outsourced radiology. They argue that each type of knowledge is at least partially duplicative; thus, either can (in part) substitute for the other, making the joint learning benefit of the two types of experience less than the sum of the individual learning benefits.

If the two types of experience may have a substitutive relationship in steady state, how might negative news lead to a different relationship? From an expected utility standpoint it is not clear that it would. The same logic from above applies as either type of experience could help an individual better understand the implications of negative news. However, it is from a behavioral standpoint that the possibility of a complementary relationship arises. Prior work examining escalation of commitment has considered either the individual effect or the effect of a group making decisions (Bazerman et al. 1984; Sleesman et al. 2012). Here we apply this logic of both effects to the eventual decision of the individual. As discussed above, individual experience may enhance an egocentric bias that leads to a greater likelihood of choosing the same decision after negative news is received. Greater group experience may reinforce and amplify this effect. Simply put, an individual looking for reasons to self-justify his decision may find it easier to do so when others surrounding him are going through the same process. Thus, the individual's experience and the experiences of others may jointly interact, leading the focal individual to be more likely to make the same operational decision. 
These discussions lead us to two propositions that we test. First, prior to negative news, we expect an individual's experience with an operational decision and others' experience with the same decision to have a substitutive relationship on subsequent decisions (Hypothesis 4A). After negative news we expect to see a complementary effect between the two types of experience (Hypothesis 4B).

Therefore, we hypothesize:

HYPOTHESIS 4A: In steady state, individuals' experiences and others' experiences will show a substitutive relationship with the likelihood that the individual makes the same operational decision.

HYPOTHESIS 4B: After receiving negative news about an operational decision, individuals, experiences and others' experiences will show a complementary relationship with the likelihood that the individual makes the same operational decision.

\section{Study 1: Cardiologists, Stent Selection, and Negative News}

\subsection{Setting}

Our first study examines the operational decision of production technology choice. Here, we examine the decisions of interventional cardiologists who perform percutaneous coronary interventions (PCI), commonly known as angioplasties. PCI is a non-surgical procedure that is used to treat narrowed coronary arteries of the heart. The candidate for an angioplasty has one or multiple levels of obstruction in the coronary arteries that supply oxygenated blood to the heart muscle. Extensive blockage can lead to limited physiological functioning for the patient, and also increases the risk of a myocardial infarction (heart attack). During an angioplasty, a cardiologist inserts an intravenous catheter, which is guided to the site of the blockage in the vessel. The catheter is then used to clear the blockage. In many cases, the coronary vessels have an increased likelihood of collapsing following the removal of the arterial blockage. To prevent such a collapse (re-stenosis), a cardiac stent (a hollow, cylindrical metal mesh) is inserted inside the vessel at the location of the blockage; this stent thus serves as a scaffolding to hold the vessel walls in place. This procedure has been used to benefit many patients over the last few decades, initially using bare-metal stents. However, even after the insertion of the stent there is a likelihood of a blockage reoccurring at the site of the metal stent (or re-stenosis).

To reduce the likelihood of restenosis, several medical device companies developed drug-eluting stents (DES), which release small amounts of drugs to prevent the formation of blockages. Procedurally, inserting a drug-eluting stent is similar to inserting a bare-metal stent. When the Food and Drug Administration (FDA) approved drug-eluting stents for marketplace use in April 2003, key stakeholders including Medicare and the leading private insurance companies agreed to incur the additional costs of the use of the drug-eluting stents. As such, there was no financial disincentive to adopt the new stents. 
Given the procedural similarity of the drug-eluting stents to the existing bare-metal stents, and given the lack of a financial disincentive, the adoption of the drug-eluting stents was rapid and significant, rising to $90 \%$ of the entire cardiac stent market in a short period of time (Grines 2008).

However, by the fall of 2006, reports of adverse outcomes, specifically associated with late stent thrombosis (or the formation of blood clots), began to emerge. To address these concerns, the FDA convened a panel of experts (the Circulatory System Devices Advisory Panel) to fully characterize the risks of the drug-eluting stents (Grines 2008). The FDA panel concluded that the risks of late stent thrombosis did not offset the benefits of drug-eluting stents, when used appropriately. However, the panel warned that there were greater risks when the new stents were used off-label (on more complex patients). Finally, the FDA noted that it "does not regulate how drug-eluting stents are used by individual clinicians in the practice of medicine." It also noted that higher complex cases are associated with a greater degree of risk of adverse outcome.

It is important to note that the FDA did not issue a product recall or take any punitive measure for the use of the new stent. The FDA announcement amounted to guidance stating that physicians were best able to understand the risks of the drug-eluting stents and that they should exercise caution, particularly when treating higher-risk (or off-label) cases. However, this announcement permits the researcher to answer important questions about how individuals (in this case interventional cardiologists) respond to external information. Specifically, to what extent do individuals respond to the news? How does the reaction to the news vary across individual physicians? In particular, is an individual's response likely to be tempered by personal experience with the drug-eluting stents? Similarly, cardiologists may view the experience of their peers as (imperfect) substitutes for their own experiences. Therefore, they may be less influenced by the FDA announcement when surrounded by peers with extensive experience with the new stents.

This setting is ideal for examining the production technology choice decisions of individuals (described in Section 2) for several reasons. First, for an interventional cardiologist, performing a highly specialized task with PCI, it may not always be obvious which tool is the ideal one to use. Therefore, specialists tend to rely on various sources of information, including experts (such as the FDA), their peers, and their own experience with the product. Our data set allows us to track usage over a 6-year period of time, and therefore examine the impact of past experience on current usage decisions. Second, because the FDA's announcement was not anticipated, it therefore constitutes a natural experiment. As such, this event allows us to generate a clean identification for the effect of a negative announcement on technology usage. Finally, cardiac care is a high-volume sector of healthcare, accounting for over a third of all Medicare spending (AHA 2008). The sheer economic significance and the impact on public health of this setting alone make it worthy of extensive research. 


\subsection{Data}

The data for our study comes from the Pennsylvania Health Cost Containment Council (PHC4). The dataset consists of all PCI procedures performed in the entire state of Pennsylvania between the years 2003 (when the drug-eluting stents first became available in the marketplace) and 2008. This includes information on a total of 147,010 PCI procedures performed by 399 cardiologists over the 6-year period. Our outcome variable of interest is the technology choice of the cardiologists performing the angioplasties; of all the PCI procedures performed during the period of observation, 38,707 involved a bare-metal stent, and 108,303 involved a drug-eluting stent. Given that ten patients are missing controls and one hospital has only two procedures, both with the same outcome, these twelve observations are dropped from our full model leaving us with a final sample of 146,998.

Each observation in the dataset provides information on the quarter and year in which the procedure was performed. This allows us to account for various temporal sources of heterogeneity, including trends and seasonality. Figure 1 provides a time series of the overall usage of stents (both baremetal and drug-eluting) during the period of study. The vertical line represents the quarter in which the FDA convened the panel of experts. We see a dramatic drop in the overall market-level adoption of drugeluting stents that coincides with a significant uptake of bare-metal stents.

There is an unequivocal impact of the FDA panel on the overall usage of the drug-eluting stents; the goal of our study is to quantify the magnitude of this effect. Moreover, the technology choice of stent for any given patient is likely to be impacted by a number of other factors. Thus, we obtain patient-level characteristics, including demographic factors such as age, gender, and race. In addition, we observe the type of payer and the specific hospital where the patient was admitted. We obtained a unique identifier for each operating cardiologist, which allows us control for various unobserved sources of physician-level heterogeneity. Collectively, these factors are used to control for the physician's choice of the type of stent (drug-eluting or bare-metal).

We also observe a unique sequence number associated with each patient, which allows us to determine the order in which a given physician treated the assigned patient. The combination of the unique physician identifier and the sequence of the patients (along with the technology choice for the patients treated) allow us to track the experience of the physician with the drug-eluting stents (based on their completed procedure volume) over the period of study.

We also observe the organization (i.e., hospital) in which the cardiologist performed the procedure. This not only allows us to account for the organization-specific drivers of physician performance (by using a hospital fixed effect) but also allows us to identify the peers of a given cardiologist. Specifically, for any given cardiologist $p$, we define her peers as the set of cardiologists who practice in the same hospital as cardiologist $p$. One of our hypotheses is that the technology choice of a 
given physician depends on the choices made by the other cardiologists in her peer group. To estimate the experience of the peers, we define cumulative peer experience by aggregating the experience of drugeluting stents for all of the peers of a given physician up to a given time $t$.

Collectively, the aforementioned variables allow us to examine the technology choice by individual physicians in determining the type of stent used in a given patient, and the extent to which the decision is affected by their experience with the stent, the experience of their peers with the stent, the FDA panel, and a number of patient, hospital, and physician level factors. Table 1 displays a summary of the case volumes and stent-usage decisions for the cardiologists in our sample, and Table 2 provides a correlation matrix of the variables we examine.

\subsection{Empirical Analysis Strategy}

The goal of our study is to estimate the choice of a cardiologist to use a drug-eluting stent, compared to its alternative (the bare-metal stent), and the extent to which this decision is moderated by the negative news, a cardiologist's prior experience with drug-eluting stents, and the experience of peers with the drug-eluting stents.

In the discussions below, the subscript $i$ denotes the patient, $p$ denotes the physician, $h$ denotes the hospital, and $t$ denotes time. As described earlier, the decision variable that we study is the choice to use a drug-eluting stent. Specifically, $D E_{i p h t}=1$ if patient $i$, who had an angioplasty performed by physician $p$ at hospital $h$ at time $t$, had a drug-eluting stent inserted, and 0 otherwise. We control for a number of patient-level variables, collectively denoted by the vector $\boldsymbol{X}_{\boldsymbol{i} \text {. }}$.

\subsubsection{Effect of Natural Experiment}

The identification in our model is driven by the announcement of the FDA's panel. We denote $P O S T_{t}=1$ for periods that occur after the announcement of the FDA panel and $P O S T_{t}=0$ for periods preceding it.

To investigate the impact of the FDA announcement on the adoption likelihood, we begin with the following empirical specification:

$$
\ln \left[\frac{\operatorname{Pr}\left(D E_{\text {ipht }}=1 \mid X_{i t}\right)}{1-\operatorname{Pr}\left(D E_{\text {ipht }}=1 \mid X_{i t}\right)}\right]=\alpha+\boldsymbol{X}_{i t} \beta+P_{p}+H_{h}+T_{t}+\gamma P O S T_{t}+\varepsilon_{\text {ipht }}
$$

where $P_{p}$ denotes the physician fixed effect. This allows us to account for unobserved physician level heterogeneity, including reputation, training and medical background. The hospital fixed effect, denoted by $H_{h}$ allows us to account for hospital-specific sources of heterogeneity, including patient mix, and geographic considerations. The vector $T_{t}$ includes temporal factors, including the time period (specifically a unique identifier for the quarter and year of the procedure). The time fixed effects allow us to account for sources of seasonality and trends. $\varepsilon_{i p h t}$ is the stochastic error term. The vector $\boldsymbol{X}_{i t}$ includes 
the patient-level control variables described above. Our key objective is to estimate gamma, which captures the effect of the FDA announcement on the reduction in likelihood that an individual physician uses the drug-eluting stent. Hypothesis 1 predicts that $\gamma<0$.

\subsubsection{Effect of Experience}

One of our primary explanatory variables is the cumulative volume of procedures performed by physician $p$ at time $t$ (beginning with the study period $t_{0}$ ) using a drug-eluting stent. Specifically, we define the physician's cumulative experience with the drug-eluting stents, as follows:

$$
S E L F_{p t}=\sum_{t^{\prime}=t_{0}}^{t} \sum_{i} I_{i p t^{\prime}}
$$

where $I_{\text {ipt }}=1$ if physician $p$ performed an angioplasty on patient $i$ at time $t$ using a drug-eluting stent, and 0 otherwise. To investigate the impact of physician experience on the physician's decision to continue using the technology, we begin with the following empirical specification:

$$
\begin{array}{r}
\ln \left[\frac{\operatorname{Pr}\left(D E_{\text {ipht }}=1 \mid X_{i t}\right)}{1-\operatorname{Pr}\left(D E_{\text {ipht }}=1 \mid X_{i t}\right)}\right] \\
=\alpha+\boldsymbol{X}_{i t} \beta+P_{p}+H_{h}+T_{t}+\gamma \text { POST }_{t}+\theta_{1} S E L F_{p t}+\theta_{2} P O S T_{t} \times S E L F_{p t}+\varepsilon_{\text {ipht }}
\end{array}
$$

$\theta_{1}$ provides a baseline effect of the impact of prior experience on the likelihood of a physician continuing to use drug-eluting stents. In estimating the models described above, we standardize $S E L F_{p t}$ by mean-centering it and normalizing it using the standard deviation. $\theta_{2}$ provides our estimate for the moderating effect of the physician's prior experience on the FDA announcement. Hypothesis 2 predicts that $\theta_{2}>0$.

As discussed in the hypothesis section, we postulate that a physician may rely on the experience of her peers to substitute for her own experiences with the drug-eluting stents. Our definition of a peer of physician $p$ is any cardiologist who performed an angioplasty at the same hospital where physician $p$ operates on patients. A similar definition of others' experience has been used by related work in the literature (KC and Staats 2012; KC et al. 2013). As such, we construct a variable for the experience of the peers of any given physician as follows:

$$
P E E R_{p t}=\sum_{t^{\prime}=t_{0}}^{t} \sum_{h \in H(p)} \sum_{p^{\prime} \neq p} \sum_{i} I H_{i p^{\prime} h t^{\prime}}
$$

In the specification above $H(p)$ denotes the set of hospitals where physician $p$ treats patients. $I H_{i p^{\prime} h t^{\prime}}$ is a binary variable that is equal to 1 if the peer of physician $p$ performed an angioplasty on patient $i$ at time $t$ using a drug-eluting stent, and 0 otherwise. In determining $P E E R_{p t}$, we therefore simply count all incidences of an angioplasty involving a drug-eluting stent performed by peer physicians at the 
set of hospitals $H(p)$ associated with physician $p$. To examine the effect of peer experience on a given physician's technology decision, we augment our base model with the following specification:

$$
\begin{aligned}
& \ln \left[\frac{\operatorname{Pr}\left(D E_{\text {ipht }}=1 \mid X_{i t}\right)}{1-\operatorname{Pr}\left(D E_{\text {ipht }}=1 \mid X_{i t}\right)}\right] \\
& =\alpha+\boldsymbol{X}_{i t} \beta+P_{p}+H_{h}+T_{t}+\gamma P O S T_{t}+\theta_{1} S E L F_{p t}+\theta_{2} P O S T_{t} \times S E L F_{p t}+\mu_{1} P E E R_{p t} \\
& +\mu_{2} P O S T_{t} \times P E E R_{p t}+\varepsilon_{i p h t}
\end{aligned}
$$

$\mu_{1}$ provides a baseline effect of the impact of a peer-level experience on the likelihood of a given physician continuing to use drug-eluting stents. To facilitate interpretation of the coefficient, we normalize the explanatory variable $P E E R_{p t}$ by mean centering and normalizing it. We expect that the peer effect is positive; that is, a physician is more likely to use the stent if her peers also use the product. However, the impact of the negative news on the likelihood of the physician continuing to use the drug-eluting stent is likely to be moderated by the experiences of the peers. Thus, as Hypothesis 3 predicts, we expect that $\mu_{2}>$ 0 .

\subsubsection{Substitutive or Complementarity Effects}

We next examine the possible substitutive or complementary effects of one's own and peer-level experience. As postulated in Hypothesis 4, one's own experience and the experience of peers are likely to serve as substitutes prior to the disclosure of negative news. To examine these effects, we employ the following empirical specification:

$$
\begin{aligned}
& \ln \left[\frac{\operatorname{Pr}\left(D E_{\text {ipht }}=1 \mid X_{i t}\right)}{1-\operatorname{Pr}\left(D E_{\text {ipht }}=1 \mid X_{i t}\right)}\right] \\
& =\alpha+\boldsymbol{X}_{i t} \beta+P_{p}+H_{h}+T_{t}+\gamma P O S T_{t}+\theta_{1} S E L F_{p t}+\mu_{1} P E E R_{p t}+\varphi_{1} S E L F_{p t} \\
& \times P E E R_{p t}+\varepsilon_{i p h t}
\end{aligned}
$$

A negative experience for $\varphi_{1}$ would provide support for Hypothesis 4A that peer experience and one's own experience with the stent are substitutes.

However, the announcement of the negative news may alter how individuals perceive the role of one's own experience and the experience of their peers. The possibility of an escalation commitment described in the arguments leading up to Hypothesis 4B would suggest that after the announcement of the negative news, one's own experience and the experience of peers have a complementary effect. To examine this possibility, we augment our empirical specification to include the policy interaction terms: 


$$
\begin{aligned}
& \ln \left[\frac{\operatorname{Pr}\left(D E_{\text {ipht }}=1 \mid X_{i t}\right)}{1-\operatorname{Pr}\left(D E_{\text {ipht }}=1 \mid X_{i t}\right)}\right] \\
& =\alpha+\boldsymbol{X}_{i t} \beta+P_{p}+H_{h}+T_{t}+\gamma \text { POST }_{t}+\theta_{1} S E L F_{p t}+\theta_{2} \text { POST }_{t} \times S E L F_{p t}+\mu_{1} P E E R_{p t} \\
& +\mu_{2} \mathrm{POST}_{t} \times P E E R_{p t}+\varphi_{1} S E L F_{p t} \times P E E R_{p t}+\varphi_{2} P O S T \times S E L F_{p t} \times P E E R_{p t} \\
& +\varepsilon_{\text {ipht }}
\end{aligned}
$$

A positive coefficient for the term $\varphi_{2}$ would provide support for Hypothesis 4B.

\subsection{Results}

We find that the FDA announcement has a significant impact (Table 3, model 1 estimate $-1.0, \mathrm{p}<$ 0.01) on the likelihood of the physicians continuing to use the drug-eluting stents. We estimated the robustness of this result using various model specifications. In particular, the exclusion of the physician fixed effect (specification 3) or the hospital fixed effect (specification 2) had no appreciable impact on the magnitude of the estimates. Similarly, the exclusion of patient-level controls (specification 4) also did not impact our estimate. Given that the FDA announcement effectively functions as an exogenous shock, independent of physician, hospital, or patient-level considerations, this result in not unexpected. However, the net impact of this announcement - a sizeable 37\% reduction in the use of the drug-eluting stents constitutes a significant impact on the decisions of interventional cardiologists across the entire market.

Next, we look at the independent effects of self and peer experiences on the response to the announcement. Our models include the physician fixed effects, which allow us to account for physicianspecific sources of heterogeneity; in other words, the identification is driven by intra-physician intertemporal variation in the level of experience with the product and the exogenous shock due to the negative announcement. We find (Table 4) that prior self-experience attenuates the impact of the policy. Specifically, a physician with greater experience with the drug-eluting stent is more likely to discount the effect of the negative announcement, supporting Hypothesis 2. All the coefficients corresponding to the interaction between self-experience and the policy term are positive (specifications 1, 2, and 5). The magnitude of the effect suggests that a physician whose experience with the drug-eluting stent increases by one standard deviation of the procedural volume leads to an increase of $9.1 \%$ (specification 1 ) in the likelihood of using the drug-eluting stents following the negative announcement.

We next examine whether peer experience moderates the impact of the FDA announcement on subsequent stent selection (Table 4, specifications 3, 4, and 5). Specifically, we see (specification 3) that the coefficient representing the interaction between the policy impact and the experience of peers has a value of $0.0515(\mathrm{p}<0.01)$. This means that a one standard deviation increase in the volume of peer experiences is associated with an attenuation of the effect of the policy announcement by $5.3 \%$. In other words, following the policy announcement, each standard deviation increase in the experience of peers 
leads to a $5.3 \%$ increase in the likelihood that a physician continues to use drug-eluting stents. These results provide support for Hypothesis 3.

Next, we consider the complementarity and substitutive effects of peer and self-experiences. The interaction between peer and self-experience has a negative coefficient (Table 5). The direction of this coefficient is unchanged across specifications 1-3, which vary in the inclusion of the FDA announcement variable. This set of results provides support for Hypothesis 4A, which posits that in the preannouncement period, peer experiences and one's own experiences serve as substitutes.

Columns 3 and 4 explore the effect of the interaction term after the implementation of the policy. We find that the coefficient on the interaction term (policy $\mathrm{x}$ self-experience $\mathrm{x}$ peer-experience) is positive. In column 4, the magnitude of the coefficient without the inclusion of the 2-way interaction terms involving the post-policy announcement is $-0.042(\mathrm{p}<0.01)$, and the magnitude of the controls with the three 2-way interaction terms is $0.027 \mathrm{p}<0.1$ ). This provides support for Hypothesis 4B suggesting that self-experience and the experience of peers effectively function as complements after the negative announcement. In other words, physicians are more likely to continue to use the new technology when their own past experiences are reinforced by the experience of their peers.

In our field data we are able to observe actions that are consistent with our hypotheses. However, we do not have mechanism data to support our hypotheses. Therefore, we now turn to the laboratory to examine our hypotheses in more detail. First, we investigate whether greater individual experience leads to greater escalation of commitment to an operational decision following negative news (H2) and then we explore whether greater experience from others leads to greater escalation of commitment to an operational decision following negative news (H3).

\section{Study 2: Self-Experience, Negative News, and Escalation of Commitment}

Hypothesis 2 suggests that individuals who have more experience (and thus feel like experts) are less likely to react to negative news than those who have less experience. We tested this hypothesis using an escalation of commitment paradigm, where participants learn that a previous operational decision they made turned out to be the wrong decision. In this study, we use a paradigm of deciding where to allocate funding within a business. This is a common operational decision that can be found not only in the research and development context (Chao et al. 2009), but also other settings such as capacity allocation (Campbell and Frei 2011) or supplier selection (Van Mieghem 1999). An additional benefit of this paradigm is that it draws on prior research (Staw 1976) and extends it through the manipulation of experience. Reacting to negative news in this study is assessed as continuing to invest in the same decision even after learning that an alternative course of action would be more beneficial. 
Participants. Three-hundred forty-six U.S-based participants on Amazon MTurk ( $M_{\mathrm{age}}=32.5$, $S D=8.76,58 \%$ male) participated in the study in exchange for a $\$ 1.50$ payment. We calculated our sample size based on an estimate of an effect size $d=.3$, requiring a sample size of approximately 350 participants for a study powered at $80 \%$.

Manipulation of expertise. To conceptually replicate and extend our field results we need an experience manipulation that taps into similar concepts but that can be done in the short amount of time permitted by lab studies. Simply having individuals execute a task, is unlikely to replicate a cardiologist's many years of training and experience. However, it is possible to manipulate an individual's feelings of expertise such that she feels more (or less) like an expert when making a decision. Our hypotheses are based on an individual's self-perception of expertise. This self-perception of expertise is generated by cardiologists naturally in the field; in our lab setting, our experimental design allows us to manipulate the subject's perception of expertise. Our lab study extends the field evidence we obtained in Study 1 in another important way: rather than measuring experience, we directly manipulated it - thus allowing us to causally test the prediction that perceived expertise leads people to be less responsive to negative news.

In this study, we manipulated participants' perceived expertise by asking them to answer a very easy or very difficult general-knowledge quiz. In particular, participants were randomly assigned either to a condition that asked 20 easy trivia questions ("In what North American country is the city of Toronto located?" "Where in the human body is food digested?") or to a condition that asked a series of 20 difficult trivia questions ("What is South America's highest mountain?," "Who is credited with inventing the wristwatch in 1904?"). These questions were pretested in prior research to be very easy or very difficult to answer correctly (Moore and Healy 2008).

Procedure. Participants were told that the study consisted of two different tasks. They first completed the first part of the decision-making task developed by Staw (1976). Playing the role of financial vice president for a fictional company, participants were asked to choose which of two company divisions should receive $\$ 5$ million in research and development (R\&D) funds. They reviewed pastearnings data, with which the future earnings of each division would ostensibly be simulated, and learned that if earnings in their chosen division exceeded earnings in the other division, they would be entered into a \$20 lottery. Participants were told that the simulation of financial data would take a few minutes and were asked to complete the second task in the meantime.

The second task consisted of our manipulation of perceived expertise. Half of the participants received 20 easy trivia questions, and half received 20 difficult trivia questions. The instructions to the trivia questions read

In this second task, you will respond to a set of trivia questions. If you are one of the 10 participants chosen at random at the end of the study, you will earn $\$ .50$ for each correct answer 
you provide. You will have 30 seconds to answer each question. At the end of 30 seconds, even if you have not answered the question, the computer will automatically advance to the next question. Please try to provide at least your best guess for each question, but only give one answer. You are not penalized for wrong answers.

After answering the trivia questions, participants saw the correct answers to each, and were then asked to indicate how well they felt they had performed on the quiz on a 7-point likert scale $(1=$ extremely poorly, 7 = extremely well). Using a similar 7-point likert scale (ranging from $1=$ very little, to 7 = extremely), they also answered three questions we used as manipulation check: 1) "How much of an expert do you feel right now?" 2) "How capable do you feel right now?" and 3) "How accomplished do you feel right now?" We averaged participants' answers across these three items to create a measure of perceived expertise $(\alpha=.92)$.

Next, all participants viewed the results of the simulation of financial data for the next five years, which always indicated that the division not chosen to receive the $\$ 5$ million in R\&D funds had achieved higher earnings. Everyone then learned that $\$ 10$ million more in R\&D funds were now available, and they were asked to choose how to allocate these funds between the two divisions (in any proportion they chose). They further learned that this second investment would also be simulated and could earn them another entry to the \$20 lottery. Reinvestment in the underperforming division that received the original R\&D funds was the primary measure of escalation of commitment (Staw 1976). Regardless of their investment choices, all participants were entered into the lottery.

Dependent measure. Reinvestment in the underperforming division was assessed using a multichoice question. Participants were asked to indicate how they would like to allocate the $\$ 10$ million R\&D funding by choosing one of the following 11 options:

- $\quad \$ 10 \mathrm{M}$ to Industrial Products and $\$ 0 \mathrm{M}$ to Consumer Products

- $\quad \$ 9 \mathrm{M}$ to Industrial Products and $\$ 1 \mathrm{M}$ to Consumer Products

- $\quad \$ 8 \mathrm{M}$ to Industrial Products and $\$ 2 \mathrm{M}$ to Consumer Products

- $\quad \$ 7 \mathrm{M}$ to Industrial Products and $\$ 3 \mathrm{M}$ to Consumer Products

- $\quad \$ 6 \mathrm{M}$ to Industrial Products and $\$ 4 \mathrm{M}$ to Consumer Products

- $\$ 5 \mathrm{M}$ to Industrial Products and $\$ 5 \mathrm{M}$ to Consumer Products

- $\quad \$ 4 \mathrm{M}$ to Industrial Products and $\$ 6 \mathrm{M}$ to Consumer Products

- $\$ 3 \mathrm{M}$ to Industrial Products and $\$ 7 \mathrm{M}$ to Consumer Products

- $\quad \$ 2 \mathrm{M}$ to Industrial Products and $\$ 8 \mathrm{M}$ to Consumer Products

- $\quad \$ 1 \mathrm{M}$ to Industrial Products and $\$ 9 \mathrm{M}$ to Consumer Products

- $\$ 0 \mathrm{M}$ to Industrial Products and $\$ 10 \mathrm{M}$ to Consumer Products 
Depending on the first division they chose, the labels of the two divisions varied in the options participants saw. We used participants' answers to this question as the main dependent measure in our analyses. The more participants decided to keep investing in their initial investment decision (after they received information that it led to a poor outcome), the higher their escalation of commitment. Escalation of commitment was assessed on the 1-11 scale above, with 1 representing no investment in the initiallychosen products and $\$ 10 \mathrm{M}$ in the alternative products (no escalation of commitment), and 11 representing investment of the full $\$ 10 \mathrm{M}$ in the initially-chosen products (highest level of escalation of commitment).

\subsection{Results}

Table 6 shows the descriptive statistics of the variables captured in Study 2 by condition.

Manipulation check. As expected, participants reported feeling they had performed better in the easy-quiz condition than in the difficult-quiz condition, $t(343)=12.91, \mathrm{p}<.001$. They also reported feeling more like experts in the easy-quiz condition than in the difficult-quiz condition, $t(344)=9.14$, $p<$ .001 .

Escalation of commitment. Consistent with our second hypothesis, participants who felt more like experts (i.e., those in the easy-quiz condition) reinvested larger amounts of money in the underperforming division as compared to participants who felt less like experts (i.e., those in the difficultquiz condition), $t(344)=2.92, p=.004$. Thus, expert participants escalated their commitment more than those who felt less expert.

\section{Discussion}

The results of Study 2 show that, as we predicted in our second hypothesis, individuals who feel like experts are less likely to react to negative news than those who perceive themselves as having less experience or knowledge.

\section{Study 3: Peer Experience, Negative News, and Escalation of Commitment}

Our third hypothesis suggested that after receiving negative news about an operational decision, individuals who are around others with more experience are more likely to stick to their initial decision than individuals who are around others with less experience because they imitate the choice of the perceived experts. That is, we predicted that those around others with more experience would be less likely to react to negative news as compared to individuals around others with less experience. Similarly to the approach we used in Study 2, we tested this hypothesis using another escalation of commitment paradigm, where participants learned that a previous investment decision they made is likely to be the wrong decision. Reacting to negative news in this study is assessed as continuing to invest in the same decision even after learning that not doing so would likely be more beneficial. 
Participants. One-hundred eighty-nine students from local universities in a city in the Northeastern United States $\left(M_{\mathrm{age}}=22.5, S D=2.94,48 \%\right.$ male) participated in the study in exchange for a \$20 payment. The study was the first one in a series of three unrelated studies that kept participants in the lab for about an hour. Upon their arrival to the laboratory, participants were randomly assigned to a threeperson group. The experimenter informed them that they would complete tasks individually and as a team throughout the study.

Design. The study included two conditions: high expertise condition and low expertise condition. Each team was randomly assigned to one of the two conditions.

Procedure. After receiving some initial instructions, participants sat at private cubicles in front of a computer and answered some demographic questions about their age, race, and gender. Next, the instructions informed them that their first task was to respond to a series of 20 trivia questions individually and that they had 45 seconds to answer (type in) an answer to each question. After the 45 seconds, the survey would advance automatically, regardless of whether they had answered the question or not. There were two versions of the quiz: difficult and easy (as in Study 2). In the low-expertise condition, all three members took the difficult quiz. In the high-expertise condition, two members took the difficult quiz and one took the easy quiz. Note that the group members did not know the answers of other members nor the type of test they took. In fact, they were unaware of the existence of two different tests.

Upon completion of the trivia task, participants were shown the correct answers to the quiz together with the answers they had provided so that they could record the number of questions they had answered correctly. Participants also answered a short questionnaire. First, they indicated how well they felt they performed on the quiz (from 1=Extremely poorly, to $7=$ Extremely well). They also indicated how much of an expert, how capable, and how accomplished they felt in that moment, using 7-point scales (from 1=Very little, to 7=Extremely), as in Study 2. We averaged their answers across these three items to create a measure of perceived expertise $(\alpha=.88)$, which we used as a manipulation check.

Next, the instructions informed participants that they would complete a decision-making task. The instructions read:

In just a minute, you'll meet with the members of your team to discuss the following situation. Please take a minute or two to read this carefully and think through your answer, and then click on $>>$.

As the president of an airline company, you have invested 10 million dollars of the company's money into a research project. The purpose was to build a plane that would not be detected by conventional radar, in other words, a radar-blank plane. When the project is $90 \%$ completed, 
another firm begins marketing a plane that cannot be detected by radar. Also, it is apparent that their plane is much faster and far more economical that the plane your company is building. The question is: should you invest the last $10 \%$ of the research funds to finish your radar-blank plane?"

The scenario is an escalation-of-commitment task developed by Arkes and Blumer (1985). Choosing to invest the remaining $\$ 1$ million to complete the project; an affirmative response indicates escalation of commitment despite the poor results of the initial investment (Arkes and Blumer 1985).

The experimenter handed out a sheet of paper with the problem-solving task on it to each team so that they could discuss the scenario. Team members were asked to indicate their team number and trivia test scores on the paper so that they could identify the person with the highest quiz score, the person with the second highest quiz score, and the person with the lowest quiz score. We used this procedure to encourage members in the high-expertise condition groups to believe that one of them was an expert. Participants were told that the ranking of their score determined the sequence they would follow in reporting their answers to the decision-making task. In this way, we were able to measure whether group members were affected by the choices of the expert in the high-expertise condition groups and whether this influence was greater than that of the person with the highest score in the low-expertise condition groups. In groups where two group members had the same trivia quiz score, they were asked to decide randomly the order in which those two members would report their answers.

After completing this team task, participants returned to their individual cubicles, and moved on to completing another task unrelated to the current study.

\subsection{Results}

Manipulation check. As expected, participants who took the easy quiz reported feeling they had performed better $(\mathrm{M}=4.81, \mathrm{SD}=0.93)$ than those who took the difficult quiz $(\mathrm{M}=2.63, \mathrm{SD}=1.12)$, $t(187)=10.29, \mathrm{p}<.001$. They also reported feeling more like experts $\left(\mathrm{M}_{\text {easy }}=4.58, \mathrm{SD}=1.01 \mathrm{vs} . \mathrm{M}_{\text {difficult }}\right.$ $=3.05, \mathrm{SD}=1.12), t(187)=7.16, \mathrm{p}<.001$.

Escalation of commitment. Consistent with Hypothesis 2, a larger percentage of participants who felt more like experts (i.e., those who took the easy quiz andthus had the highest score in the highexpertise condition groups) decided to invest the last $10 \%$ of the research funds to finish their radar-blank plane $(84.4 \%, 27$ out of 32$)$ as compared to participants who had the highest score in groups in the lowexpertise condition (i.e., those who took the difficult quiz, $58.1 \%, 18$ out of 31 ), $\chi^{2}(1, N=63)=5.34, \mathrm{p}=$ .021 .

Influence of the perceived expert. Consistent with our third hypothesis, a larger percentage of group members who had the second-highest score in the high-expertise condition groups made the same 
decision as the perceived expert (the person in the group who had the highest score) $(87.5 \%, 28$ out of 32) as compared to participants who had the second highest score in groups in the low-expertise condition $(64.5 \%, 20$ out of 31$), \chi^{2}(1, N=63)=4.59, \mathrm{p}=.032$. Similarly, a larger percentage of group members who had the lowest score made the same decision as the perceived expert in the high-expertise condition $(90.6 \%, 29$ out of 32$)$ than in the low-expertise condition $(67.7 \%, 21$ out of 31$), \chi^{2}(1, N=63)=5.04, \mathrm{p}=$ .025 .

We also calculated the number of members in each group who made the same decision as the person with the highest score (i.e., 0, 1 or 2). Mirroring the results reported above, this number was higher in the high-expertise condition $(\mathrm{M}=1.78, \mathrm{SD}=0.49)$ than in the low-expertise condition $(\mathrm{M}=1.32, \mathrm{SD}=$ $0.75), t(61)=2.89, \mathrm{p}=.005$.

To test the robustness of our effects, we also used the number of group members in each group who made the same decision as the person with the highest score as the dependent measure in an ANOVA with our expertise manipulation and the type of decision the perceived expert made as between-subjects factors. We found a significant main effect for our expertise manipulation, $F(1,59)=6.05, \mathrm{p}=.017$, such that more group members were influenced by the decision of the perceived expert in the high-expertise condition than in the low-expertise condition. The main effect of the perceived expert's decision was also significant, $F(1,59)=6.36, \mathrm{p}=.014$, such that more group members were influenced by the decision of the perceived expert when he/she chose to continue investing versus not $(\mathrm{M}=1.73, \mathrm{SD}=0.50 \mathrm{vs.} \mathrm{M}=$ $1.11, \mathrm{SD}=0.83$ ). As expected, the interaction between our expertise manipulation and the type of decision the perceived expert made did not reach statistical significance, $F(1,59)=1.75, \mathrm{p}=.19$.

\subsection{Discussion}

The results of Study 3 provide further support for our second hypothesis, which predicted that individuals who feel like experts would be less likely to react to negative news than those who perceived themselves as having less experience or knowledge. Our results also support our third hypothesis, which predicted that people who are around peers with more experience are more likely to imitate the choice of the perceived experts as compared to those who are around peers with less experience. And given that those who feel they are expert are less likely to react to negative news, those around them show the same tendency, thus making worse decisions than those in groups without someone who is perceived to be a clear expert.

\section{Discussion and Conclusion}

Increasingly, operational decisions occur over multiple periods and are dynamic. Work examining one or two period settings or multi-period, static environments finds that individuals behave irrationally for many reasons, depending on the context, including anchoring (Schweitzer and Cachon 
2000), anticipated regret (Davis, Katok and Kwasnica 2011), demand chasing (Kremer, Minner and Van Wassenhove 2010), loss aversion (Davis, Katok and Santamaría 2014), and incorrectly incorporating relevant information (Croson and Donohue 2006; Kremer, Moritz and Siemsen 2011). Once one moves to a multi-period, dynamic setting a new challenge arises. Namely, individuals must weigh new information that they receive and then update their beliefs if they are to make subsequent decisions that maximize their expected utility (Simon 1959; Good 1962; Von Neumann and Morgenstern 2007). This requires decision makers to update their prior beliefs. Such processes can be seen in a wide variety of contexts including: labor scheduling, production tool choice, job shop scheduling, local capacity decisions, inventory ordering, R\&D allocation, pricing, and Bayesian models more generally.

In our paper, we used a field study and two lab studies to explore how individuals update their beliefs when exposed to negative news. Our empirical investigation led to four main findings. First, we find that individuals do update their beliefs in response to negative news, on average. For example, following the FDA's cautionary announcement about drug-eluting stents, cardiologists were $37 \%$ less likely to use these stents than before the announcement, on average. Second, we explore one important individual difference in such choices: experience. In both field and lab studies we consistently find that individuals who have more experience or a greater sense of experience are less likely to respond to negative news as compared to individuals with less experience. Our field setting reveals that cardiologists with one standard deviation more experience are $8.8 \%$ more likely to continue to use drug-eluting stents than are cardiologists with one standard deviation less experience. Third, we find that peer effects play an important role in individuals' responses to negative news. Individuals surrounded by one standard deviation more experienced peers are $7.1 \%$ more likely to continue using drug-eluting stents than are individuals around less experienced peers. Finally, and perhaps most surprisingly, we find a complementarity between these effects. Although self and peer experience are substitutes prior to the negative news, after the negative news is released they become complements, whereby they interact to make an individual more likely to choose a drug-eluting stent.

Each of these four results leads to a significant contribution for this paper. The first contribution comes from showing that individuals do in fact update their beliefs after negative news in multi-period, dynamic settings. Prior research shows that consumers make similar adjustments in their choices (e.g., Simonsohn 2011; Zhao et al. 2011). There is value in extending this baseline result into the operational decision setting, given that operational decision makers might be expected to allocate more attention than consumers to a decision and also have significant reputational costs to a decision. As a result, not only replicating this prior result but also documenting its effect size (Cachon 2012) is valuable in better understanding this process. Our result lends baseline support to standard operations management models that assume that individuals dynamically receive new information and then update their beliefs and make 
new decisions.

At the same time, this result suggests a number of opportunities for ongoing work. For example, explicitly modeling this partial updating is important in analytical work. In empirical work, with careful field data it may be possible to explore how individuals update their beliefs based on new information. As suggested by Bowman (1963) by examining the decision-updating process in the field, it may be possible to identify not only more detail about how the process works and potential biases that exist, but also situations where managers' local knowledge permits them to make better decisions than the system (van Donselaar et al. 2010). In addition, understanding other drivers of belief updating would be worthwhile. Possible variables to explore could include workload (KC and Terwiesch 2009; Tan and Netessine 2014; Dai et al. 2015), prior variety in experience (Narayanan, Balasubramanian and Swaminathan 2009; Staats and Gino 2012), familiarity with coworkers (Huckman, Staats and Upton 2009; Huckman and Staats 2011), or hierarchical role, such as front-line vs. management (Tucker 2007; 2015).

Our second contribution comes from examining how the individual difference of experience affects the updating process. Empirical explorations in operations have typically focused on the benefits that can accrue to individuals from acquiring the right types of experience (e.g., Huckman and Pisano 2006; Staats and Gino 2012). While acknowledging that experience may prove valuable in many settings, here we show that it may also add a problematic element to the belief-updating process. Our field results are consistent with the ill effects of egocentric bias, whereby individuals escalate commitment more than they should in response to negative news. Our lab studies allow us to trade external validity for internal validity; in so doing, we are able to show precisely that feelings of expertise can lead to greater escalation of commitment after receiving negative news. Ongoing work is needed to understand the role of experience in belief updating. For analytical research, this may involve explicitly modeling the differences across populations with different experience. Further empirical work is needed to understand whether inadequate updating simply results in lower rates of learning or instead yields curvilinearity in learning rates or even negative learning rates. Also, examining moderators of the experience relationship, such as those mentioned above (e.g., workload, variety, hierarchical level), would be worthwhile.

Third, we incorporate the role of others' experience in individual response. Prior research highlights the social nature of operational contexts. Individuals may perform better when surrounded by others with whom they've worked (Huckman et al. 2009; Huckman and Staats 2011) or alter the effort they allocate depending on their coworkers' actions (Schultz, Schoenherr and Nembhard 2010; Chan, Li and Pierce 2014). In examining others' experience, prior work has tended to focus on what one can learn from this outside or vicarious experience (Gino et al. 2010; KC et al. 2013). As is the case with individual experience, we find that others' experiences may also prove maladaptive when negative news is shared. Peer experience may provide additional knowledge but may also lead to social pressure that results in 
suboptimal updating. This creates multiple opportunities for further research. One fruitful direction for future work is to consider the diffusion of experience across an organization and evaluate how different paths and rates alter individual decisions. Empirically, there would be value to not only considering other contexts but also to evaluating moderators. This could include an exploration of whether or not individuals have experience working with the others in the group (team familiarity). Together, our finding suggests that future work must incorporate others' actions in individuals' belief-updating process.

Our fourth contribution consists in the exploration of the interaction between self-experience and peer experience. Under "normal" operating conditions, we find that the two are substitutive, in-line with prior work on learning from experience (Clark et al. 2013). However, after negative news is shared, we find that the effect is reversed, providing a clear indication of bias in our field data. After negative news, we find that the two types of experience are neither substitutive nor even additive, but rather multiplicative in predicting an individual's likelihood of continuing to make the same decision. The lesson is an important one in operating system design. In this case, the joint effects of self-experience and peer experience lead individuals to respond to negative news by making the same decision as before.

\subsection{Limitations}

We performed additional analyses to examine whether a negative outcome impacts the stent choice decision. Specifically, does a patient death impact the future stent choice decision of a cardiologist? In our data, we find that mortality events are rare $(0.75 \%)$. In addition, in our empirical analysis, we find that such adverse outcomes do not predict stent choice; specifically, the coefficient representing adverse outcomes is not statistically significant in explaining subsequent stent choice. Furthermore, the medical literature on the topic during the period of study also appears equivocal on the topic (Camenzind, Steg and Wijns 2006; Eisenstein et al. 2007; Farb and Boam 2007). We therefore believe that the FDA announcement provides the most important explanation for stent choice variation. Specifically, the exogenous shock provides the most significant basis for the updating of physician belief, which then drives stent choice. However, there could be other factors that also play a role in this decision, and future work should seek contexts where belief updating and operational performance can be examined more closely on a simultaneous basis.

A limitation of our field-study is that we are able to observe decisions but not their underlying mechanism. In this paper, we overcome this limitation by turning to the lab, where we can more precisely investigate a causal pathway. Still, future work measuring the mechanism directly in the field would be valuable. In general, in the lab we lose external validity in exchange for internal validity. The combination of lab and field data helps to address this loss, but future work that implements field experiments to address both concerns would be valuable. 


\subsection{Managerial Implications}

Our study has important implications for both medical professionals and operations managers more generally as they think about how to help individuals update beliefs in an uncertain world. The good news is that individuals do update their beliefs after the announcement of negative news. In our field context we see an average change of $37 \%$. This suggests that managers should be clear in the communication of negative news that occurs in operating environments to help individuals make better decisions.

However, our findings show that simply presenting new negative information should not be taken as a panacea. Managers must be prepared for challenges in belief updating to occur. A necessary step is to understand where differences in belief updating may occur. Assuming that all individuals will update their beliefs similarly is wrong. While data analytical tools may reveal important new information for decision-making and operations management models may yield better decision-making algorithms, our work highlights that these approaches do not operate in a vacuum. Rather, it is also important to incorporate behavioral work in order to design decision settings that present the necessary information, with tools to interpret it in ways that help decision makers respond successfully. Our research shows that managers must be prepared to address experienced individuals differently from inexperienced individuals. Managerial awareness is one step, but also managers will need to design interventions. These interventions could include making the experienced individual aware of the risk or also engaging the experienced individual in perspective taking exercises to understand the ways a less experienced person might understand the situation better.

In addition, when working with groups that have experience managers must be aware that peer effects may alter individuals' decisions. Sharing this danger with groups may help, but managers must also think about operational system design in communicating information and then monitoring and supporting subsequent decisions. Overall, managers must incorporate data, models, and behavior in order to improve their operations and make better decisions. Behavioral operations management is a valuable approach to tackle these topics.

\subsection{Conclusion}

Multi-period, dynamic operations models rely upon decision makers to update their beliefs based on new information. In this paper, we investigate that process in the field and in the lab. We find that although individuals do respond to negative news, the rate at which they do so is influenced by self-experience, peer experience, and their interaction. Addressing such biases is important not only for operational scholars in the development of analytical models and operating managers involved in system design, but for everyday decision makers. 


\section{References}

Arkes, H. and C. Blumer (1985). "The psychology of sunk cost." Organ. Behav. Human Decision Processes 35(1): 124-140.

Arlotto, A., S. E. Chick and N. Gans (2014). "Optimal hiring and retention policies for heterogeneous workers who learn." Management Sci. 60(1): 110 - 129.

Asch, S. E. (1965). Effects of group pressure upon the modification and distortion of judgements. Basic Studies in Social Psychology. H. Proshansky: 393-411.

Bazerman, M. H., T. Giuliano and A. Appelman (1984). "Escalation of commitment in individual and group decision making." Organ. Behav. Human Decision Processes 33(2): 141-152.

Bendoly, E., K. Donohue and K. L. Schultz (2006). "Behavior in operations management: Assessing recent findings and revisiting old assumptions." J. of Operations Management 24(6): 737-752.

Bonaccio, S. and R. S. Dalal (2006). "Advice taking and decision-making: An integrative literature review, and implications for the organizational sciences." Organ. Behav. Human Decision Processes 101(2): 127-151.

Bowman, E. H. (1963). "Consistency and optimality in managerial decision making." Management Sci. 9(2): 310-321.

Brown, G. W., J. Y. Lu and R. J. Wolfson (1964). "Dynamic modeling of inventories subject to obsolescence." Management Sci. 11(1): 51-63.

Cachon, G. (2012). "What is interesting, in operations management?" Manufacturing Service Oper. Management 14(2): 166-169.

Camenzind, E., P. G. Steg and W. Wijns (2006). "Safety of drug-eluting stents: a meta-analysis of 1st generation DES programs." World Congress of Cardiology.

Camerer, C. and D. Lovallo (1999). "Overconfidence and excess entry: An experimental approach." American Economic Review 89(1): 306-318.

Campbell, D. and F. X. Frei (2011). "Market heterogeneity and local capacity decisions in services." Manufacturing Service Oper. Management 13(1): 2-19.

Chan, T. Y., J. Li and L. Pierce (2014). "Compensation and peer effects in competing sales teams." Management Sci. 60(8): 1965-1984.

Chao, R., S. Kavadias and C. Gaimon (2009). "Revenue driven resource allocation and effective NPD portfolio management." Management Sci. 55(9): 1556-1569.

Chevalier, J. A. and D. Mayzlin (2006). "The effect of word of mouth on sales: Online book reviews." Journal of Marketing Research 43(August): 345-354.

Clark, J. R., R. S. Huckman and B. R. Staats (2013). "Customer specificity and learning: Evidence from outsourced radiological services." Organ. Sci. 24(5): 1539-1557.

Clark, K. B. (1989). "Project scope and project performance: The effect of parts strategy and supplier involvement on product development." Management Sci. 35(10): 1247-1263.

Croson, R. and K. Donohue (2006). "Behavioral causes of the bullwhip effect and the observed value of inventory of information." Management Sci. 52(3): 323-336.

Cutler, D. M., R. S. Huckman and M. B. Landrum (2004). "The role of Information in medical markets: An analysis of publicly reported outcomes In cardiac surgery." American Economic Review 94(2): 342-346.

Dai, H., K. L. Milkman, D. A. Hofmann and B. R. Staats (2015). "The impact of time at work and time off from work on rule compliance: The case of hand hygiene in healthcare." J. Appl. Psych. 100(3): 846-862.

Dantzig, G. (1955). "Linear programming under uncertainty." Management Sci. 1(2): 197-206.

Davis, A. M., E. Katok and A. M. Kwasnica (2011). "Do auctioneers pick pptimal reserve prices?" Management Sci. 57(1): 177-192.

Davis, A. M., E. Katok and N. Santamaría (2014). "Push, pull, or both? A behavioral study of how the allocation of inventory risk affects channel efficiency." Management Sci. 60(11): 2666-2683. 
Deming, W. E. (1986). Out of the crisis. Cambridge, Mass., Massachusetts Institute of Technology, Center for Advanced Engineering Study.

Eisenstein, E. L., K. J. Anstrom, D. F. Kong, L. K. Shaw, R. H. Tuttle, D. B. Mark, . . D. E. Kandzari (2007). "Clopidogrel use and long-term clinical outcomes after drug-eluting stent implantation." Jama 297(2): 159-168.

Farb, A. and A. B. Boam (2007). "Stent thrombosis redux - The FDA perspective." N. Engl. J. Med. 356(10): 984-987.

Festinger, L. (1957). A Theory of Cognitive Dissonance. Stanford, CA, Stanford University Press.

Fisher, M. L. and C. D. Ittner (1999). "The impact of product variety on automobile assembly operations: Empirical evidence and simulation analysis." Management Sci. 45(6): 771-786.

Fryer, J. S. (1975). "Effects of shop size and labor flexibility in labor and machine limited production systems." Management Sci. 21(5): 507-515.

Gans, N., G. Knox and R. Croson (2007). "Simple models of discrete choice and their performance in bandit experiments." Manufacturing Service Oper. Management 9(4): 383-408.

Garland, H., C. A. Sandefur and A. C. Rogers (1990). "De-escalation of commitment in oil exploration: When sunk costs and negative feedback coincide." J. Appl. Psych. 75(6): 721-727.

Gino, F. (2008). "Do we listen to advice just because we paid for it? The impact of advice cost on its use." Organ. Behav. Human Decision Processes 107(2): 234-245.

Gino, F., L. Argote, E. Miron-Spektor and G. Todorova (2010). "First, get your feet wet: The effects of learning from direct and indirect experience on team creativity." Organ. Behav. Human Decision Processes 111(2): 102-115.

Gino, F. and G. P. Pisano (2008). "Toward a theory of behavioral operations." Manufacturing Service Oper. Management 10(4): 676-691.

Godes, D. and D. Mayzlin (2004). "Using online conversations to study word-of-mouth communication." Marketing Science 23(4): 545-560.

Good, I. J. (1962). "How rational should a manager be?" Management Sci. 8(4): 383-393.

Goyal, M. and S. Netessine (2011). "Volume flexibility, product flexibility, or both: The role of demand correlation and product substitution." Manufacturing Service Oper. Management 13(2): 180-193.

Grines, C. L. (2008). "Off-label use of drug-eluting stents: putting it in perspective." Journal of the American College of Cardiology 51(6): 615-617.

Harvey, N. and I. Fischer (1997). "Taking advice: Accepting help, improving judgment, and sharing responsibility." Organ. Behav. Human Decision Processes 70(2): 117-133.

Haunschild, P. R. and M. Rhee (2004). "The role of volition in organizational learning: The case of automotive product recalls." Management Sci. 50(11): 1545-1560.

Hendricks, K. B. and V. R. Singhal (2005). "An empirical analysis of the effect of supply chain disruptions on long-run stock price performance and equity risk of the firm." Production and Operations Management 14(1): 35-52.

Huckman, R. S. and G. P. Pisano (2006). "The firm specificity of individual performance: Evidence from cardiac surgery." Management Sci. 52(4): 473-488.

Huckman, R. S. and B. R. Staats (2011). "Fluid tasks and fluid teams: The impact of diversity in experience and team familiarity on team performance." Manufacturing Service Oper. Management 13(3): 310-328.

Huckman, R. S., B. R. Staats and D. M. Upton (2009). "Team familiarity, role experience, and performance: Evidence from Indian software services." Management Sci. 55(1): 85-100.

Janis, I. L. (1982). Groupthink: Psychological Studies of Policy Decisions and Fiascoes. Boston, Houghton Mifflin.

Jeffrey, C. (1992). "The relation of judgment, personal involvement, and experience in the audit of bank loans." The Accounting Review 67(4): 802-819.

Jin, G. Z. and P. Leslie (2003). "The effect of information on product quality: Evidence from restaurant hygiene grade cards." The Quarterly Journal of Economics 118(2): 409-451. 
Judge, T. A., A. Erez and J. E. Bono (1998). "The power of being positive: The relation between positive selfconcept and job performance. ." Human Performance 11: 167-187.

KC, D. and B. R. Staats (2012). "Accumulating a portfolio of experience: The effect of focal and related experience on surgeon performance." Manufacturing Service Oper. Management 14(4): 618-633.

KC, D., B. R. Staats and F. Gino (2013). "Learning from my successes and others' failure: Evidence from minimally invasive cardiac surgery." Management Sci. 59(11): 2435-2449.

KC, D. and C. Terwiesch (2009). "Impact of workload on service time and patient safety: An econometric analysis of hospital operations." Management Sci. 55(9): 1486-1498.

Kesavan, S., B. R. Staats and W. G. Gilland (2014). "Labor-mix and volume flexibility: Evidence from a retailer." Management Sci. 60(8): 1884-1906.

Kremer, M., S. Minner and L. N. Van Wassenhove (2010). "Do random errors explain newsvendor behavior?" Manufacturing Service Oper. Management 12(4): 673-681.

Kremer, M., B. Moritz and E. Siemsen (2011). "Demand forecasting behavior: System neglect and change detection." Management Sci. 57(10): 1827-1843.

Krueger, J. I. (2003). "Return of the ego--Self-referent information as a filter for social prediction: Comment on Karniol (2003)." Psych. Rev. 110(3): 585-590.

Lapré, M. A. and I. M. Nembhard (2010). "Inside the organizational learning curve: Understanding the organizational learning process." Foundations and Trends in Technology, Information and Operations Management 4(1): 1-103.

MacDuffie, J. P. (1997). "The road to "Root Cause": Shop-floor problem-solving at three auto assembly plants." Management Sci. 43(4): 479-502.

Moore, D. A. and P. J. Healy (2008). "The trouble with overconfidence." Psych. Rev. 115(2): 502-517.

Naidu, S. S. (2010). "Three years since the FDA advisory panel on drug-eluting stents: What have we learned about off-label use and stent thrombosis?" Journal of Invasive Cardiology 22(1): 20-21.

Narayanan, S., S. Balasubramanian and J. M. Swaminathan (2009). "A matter of balance: Specialization, task variety, and individual learning in a software maintenance environment." Management Sci. 55(11): 1861-1876.

Phillips, R., A. S. Şimşek and G. v. Ryzin (2015). "The effectiveness of field price discretion: Empirical evidence from auto lending." Management Sci.

Pope, D. G. (2009). "Reacting to rankings: Evidence from 'America's Best Hospitals and Colleges'." Journal of Health Economics 28(6): 1154-1165.

Ramdas, K., K. Saleh, S. Stern and H. Liu (2010). The impact of surgical device choice on outcomes in hip replacement surgery. Research seminar, Information Systems \& Operations Management Department, Goizueta Business School, Emory University.

Reagans, R., L. Argote and D. Brooks (2005). "Individual experience and experience working together: Predicting learning rates from knowing who knows what and knowing how to work together." Management Sci. 51(6): 869-881.

Schmidt, W. and A. Raman (2015). "When supply-chain disruptions matter." Harvard Business School Working Paper(13-006).

Schultz, K. L., T. Schoenherr and D. Nembhard (2010). "An example and a proposal concerning the correlation of worker processing times in parallel tasks." Management Sci. 56(1): 176-191.

Schwab, A. (2007). "Incremental organizational learning from multilevel information sources: evidence for cross-level interactions." Organ. Sci. 18(2): 233-251.

Schweitzer, M. E. and G. P. Cachon (2000). "Decision bias in the newsvendor problem with a known demand distribution: Experimental evidence." Management Sci. 46(3): 404-420.

Shah, R., G. Ball and S. Netessine (2013). "Plant operations and product recalls in the automotive Industry: An empirical investigation."

Shah, R. and P. T. Ward (2003). "Lean manufacturing: Context, practice bundles, and performance." J. of Operations Management 21(2): 129-149.

Simon, H. A. (1959). "Theories of decision-making in economics and behavioral science." American Economic Review 49(3): 253-283. 
Simonsohn, U. (2011). "Lessons from an "Oops" at Consumer Reports: Consumers follow experts and ignore invalid information." Journal of Marketing Research 48(1): 1-12.

Sinaceur, M., C. Heath and S. Cole (2005). "Emotional and deliberative reactions to a public crisis: Mad cow disease in France." Psych. Sci. 16(3): 247-254.

Sleesman, D. J., D. E. Conlon, G. McNamara and J. E. Miles (2012). "Cleaning Up the big muddy: A meta-analytic review of the determinants of escalation of commitment." Academy Manage. $J$. 55(3): 541-562.

Smiddy, H. F. and L. Naum (1954). "Evolution of a "Science of Managing" in America." Management Sci. 1(1): 1-31.

Staats, B. R. and F. Gino (2012). "Specialization and variety in repetitive tasks: Evidence from a Japanese bank." Management Sci. 58(6): 1141-1159.

Staw, B. M. (1976). "Knee-deep in the big muddy: A study of escalating commitment to a chosen course of action." Organ. Behav. Human Decision Processes 16(1): 27-44.

Staw, B. M. (1981). "The escalation of commitment to a course of action." Acad. Management Rev. 6(4): 577-587.

Tan, T. F. and S. Netessine (2014). "When does the devil make work? An empirical study of the impact of workload on server's performance." Management Sci. 60(6): 1574-1593.

Thirumalai, S. and K. K. Sinha (2011). "Product recalls in the medical device industry: An empirical exploration of the sources and financial consequences." Management Sci. 57(2): 376-392.

Tost, L. P., F. Gino and R. Larrick (Forthcoming). "Power, competitiveness, and advice taking: Why the powerful don't listen." Organ. Behav. Human Decision Processes.

Tost, L. P., F. Gino and R. P. Larrick (2012). "Power, competitiveness, and advice taking: Why the powerful don't listen." Organ. Behav. Human Decision Processes 117(1): 53-65.

Tucker, A. L. (2007). "An empirical study of system improvement by frontline employees in hospital units." Manufacturing Service Oper. Management 9(4): 492-505.

Tucker, A. L. (2015). "The impact of workaround difficulty on frontline employees' response to operational failures: A laboratory experiment on medication administration." Management Sci.

Tversky, A. and D. Kahneman (1974). "Judgment under uncertainty: Heuristics and biases." Science 185(4157): 1124-1131.

Upton, D. M. (1997). "Process range in manufacturing: An empirical study of flexibility." Management Sci. 43(8): 1079-1092.

van Donselaar, K. H., V. Gaur, T. van Woensel, R. A. C. M. Broekmeulen and J. C. Fransoo (2010). "Ordering behavior in retail stores and implications for automated replenishment." Management Sci. 56(5): 766-784.

Van Mieghem, J. A. (1999). "Coordinating investment, production, and subcontracting." Management Sci. 45(7): 954-971.

Von Neumann, J. and O. Morgenstern (2007). Theory of Games and Economic Behavior. Princeton, NJ, Princeton University Press.

Wagner, H. and T. Whitin (1958). "Dynamic version of the economic lot size model." Management Sci. 5(1): 89-96.

Whyte, G. (1993). "Escalating commitment in individual and group decision making: A prospect theory approach." Organ. Behav. Human Decision Processes 54(3): 430-455.

Yaniv, I. (2004). "Receiving other people's advice: Influence and benefit." Organ. Behav. Human Decision Processes 93(1): 1-13.

Yaniv, I. and E. Kleinberger (2000). "Advice Taking in Decision Making: Egocentric Discounting and Reputation Formation." Organ. Behav. Human Decision Processes 83(2): 260-281.

Zhao, Y., Y. Zhao and K. Helsen (2011). "Consumer learning in a turbulent market environment: Modeling consumer choice dynamics after a product-harm crisis." Journal of Marketing Research 48(2): $255-267$. 


\section{Tables and Figures}

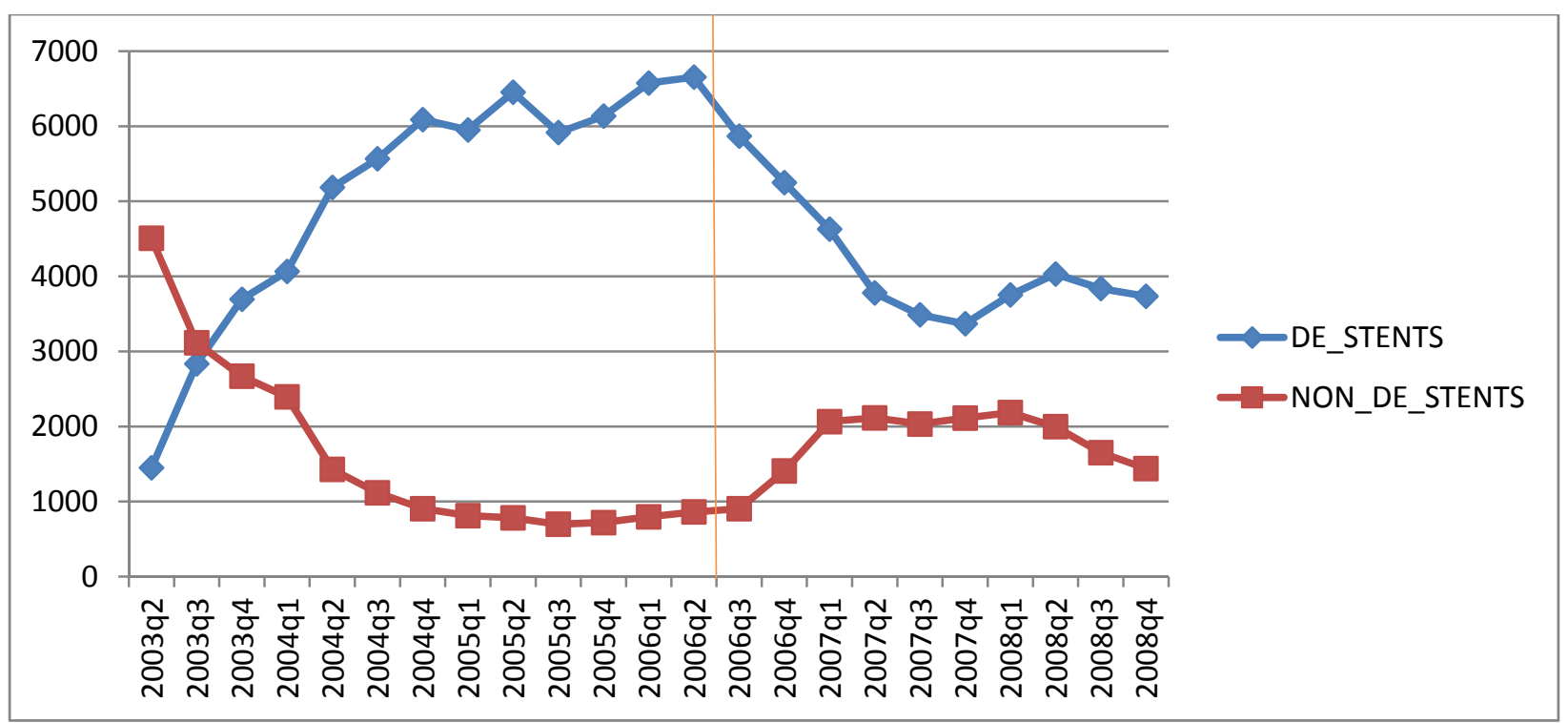

Figure 1. Total Volumes of Drug-Eluting and Non-Drug-Eluting Stents

Table 1. Summary Statistics (Standardized)

\begin{tabular}{crrrrr} 
& \multicolumn{1}{c}{ mean } & Median & \multicolumn{1}{c}{ s.d. } & \multicolumn{1}{c}{$\min$} & \multicolumn{1}{c}{$\max$} \\
\hline DE Stent Usage & 0.737 & 1.000 & 0.440 & 0.000 & 1.000 \\
Age & 64.647 & 65.000 & 11.994 & 18.000 & 101.000 \\
Self-Experience & 200.136 & 139.000 & 206.392 & 0.000 & $1,628.000$ \\
Peer Experience & $1,288.665$ & 825.500 & $1,527.555$ & 0.000 & $9,327.000$ \\
Post Policy & 0.406 & 0.000 & 0.491 & 0.000 & 1.000 \\
\hline \hline
\end{tabular}

Table 2. Correlation Coefficients

\begin{tabular}{cccccl} 
& $(1)$ & $(2)$ & $(3)$ & $(4)$ & $(5)$ \\
\hline DE stent Usage (1) & 1.000 & -0.049 & 0.081 & 0.032 & -0.069 \\
Age (2) & -0.049 & 1.000 & 0.066 & 0.047 & 0.005 \\
Self-Experience (3) & 0.081 & 0.066 & 1.000 & 0.312 & 0.032 \\
Peer Experience (4) & 0.032 & 0.047 & 0.312 & 1.000 & 0.028 \\
Post Policy (5) & -0.069 & 0.005 & 0.032 & 0.028 & 1.000 \\
\hline \hline
\end{tabular}


Table 3. Effect of Negative Announcement on Technology Usage

\begin{tabular}{ccccc}
\hline & $\mathbf{( 1 )}$ & $\mathbf{( 2 )}$ & $\mathbf{( 3 )}$ & $\mathbf{( 4 )}$ \\
\hline Hospital Fixed Effect & Yes & No & Yes & Yes \\
Physician Fixed Effect & Yes & Yes & No & Yes \\
Time Fixed Effects & Yes & Yes & Yes & Yes \\
Patient Controls & Yes & Yes & Yes & No \\
Age & $-0.0136^{* * *}$ & $-0.0136^{* * *}$ & $-0.0134^{* * *}$ & \\
& $(0.00079)$ & $(0.00079)$ & $(0.00078)$ & \\
Post Announcement & $-1.001^{* * *}$ & $-0.990^{* * *}$ & $-0.976^{* * *}$ & $-0.988^{* * *}$ \\
& $(0.0387)$ & $(0.0387)$ & $(0.0382)$ & $(0.0386)$ \\
_cons & $1.856^{* * *}$ & $2.076^{* * *}$ & $2.563^{* * *}$ & $0.917^{* * *}$ \\
AIC & $(0.227)$ & $(0.212)$ & $(0.183)$ & $(0.150)$ \\
Number of observations & $143,238.9$ & $143,500.7$ & $145,759.1$ & $144,249.0$ \\
\hline \hline
\end{tabular}

note: ${ }^{\star \star \star} p<0.01,{ }^{\star \star} p<0.05,{ }^{*} p<0.1$

Table 4. Moderating Effect of Self and Peer Experience

\begin{tabular}{|c|c|c|c|c|c|}
\hline & (1) & (2) & (3) & (4) & (5) \\
\hline Hospital Fixed Effect & Yes & Yes & Yes & Yes & Yes \\
\hline Physician Fixed Effect & Yes & Yes & Yes & Yes & Yes \\
\hline Time Fixed Effects & Yes & Yes & Yes & Yes & Yes \\
\hline Patient Controls & Yes & Yes & Yes & Yes & Yes \\
\hline Age & $\begin{array}{l}-0.0137 * * * \\
(0.000791)\end{array}$ & $\begin{array}{l}-0.0138^{* * *} \\
(0.000791)\end{array}$ & $\begin{array}{l}-0.0137^{* * *} \\
(0.000791)\end{array}$ & $\begin{array}{l}-0.0138^{* * *} \\
(0.000791)\end{array}$ & $\begin{array}{l}-0.0138 * * * \\
(0.000791)\end{array}$ \\
\hline Post Announcement & $\begin{array}{l}-0.992 * * * \\
(0.0388)\end{array}$ & $\begin{array}{l}-0.993 * * * \\
(0.0388)\end{array}$ & $\begin{array}{l}-0.999 * * * \\
(0.0387)\end{array}$ & $\begin{array}{l}-1.000 * * * \\
(0.0388)\end{array}$ & $\begin{array}{l}-0.992 * * * \\
(0.0388)\end{array}$ \\
\hline Self-Experience & $\begin{array}{l}0.0397^{* * *} \\
(0.0130)\end{array}$ & $\begin{array}{l}-0.00137 \\
(0.0151)\end{array}$ & & $\begin{array}{l}0.0454^{* * *} \\
(0.0129)\end{array}$ & $\begin{array}{l}0.00473 \\
(0.0155)\end{array}$ \\
\hline Self-Experience $x$ Post & $\begin{array}{l}0.0878^{* * *} \\
(0.0157)\end{array}$ & $\begin{array}{l}0.0883^{* * *} \\
(0.0156)\end{array}$ & & & $\begin{array}{l}0.0773^{* * *} \\
(0.0167)\end{array}$ \\
\hline Peer Experience & & $\begin{array}{l}0.0709 * * * \\
(0.0133)\end{array}$ & $\begin{array}{l}0.0710^{* * *} \\
(0.0128)\end{array}$ & $\begin{array}{l}0.0428^{* * *} \\
(0.0151)\end{array}$ & $\begin{array}{l}0.0565^{* * *} \\
(0.0154)\end{array}$ \\
\hline Peer Experience $x$ Post & & & $\begin{array}{l}0.0515^{* * *} \\
(0.0140)\end{array}$ & $\begin{array}{l}0.0522^{* * *} \\
(0.0139)\end{array}$ & $\begin{array}{l}0.0277^{*} \\
(0.0149)\end{array}$ \\
\hline _cons & $\begin{array}{l}1.891^{* * *} \\
(0.227)\end{array}$ & $\begin{array}{l}1.901^{* * *} \\
(0.227)\end{array}$ & $\begin{array}{l}1.889 * * * \\
(0.227)\end{array}$ & $\begin{array}{l}1.903^{* * *} \\
(0.227)\end{array}$ & $\begin{array}{l}1.895^{* * *} \\
(0.227)\end{array}$ \\
\hline AIC & $143,144.5$ & $143,118.0$ & $143,146.4$ & $143,136.0$ & $143,116.6$ \\
\hline Number of observations & 146,998 & 146,998 & 146,998 & 146,998 & 146,998 \\
\hline
\end{tabular}

note: ${ }^{* \star *} p<0.01,{ }^{* \star} p<0.05,{ }^{*} p<0.1$ 
Table 5. Complementary and Substitution Effects of Self and Peer Experience

\begin{tabular}{|c|c|c|c|c|}
\hline & (1) & (2) & (3) & (4) \\
\hline Hospital Fixed Effect & Yes & Yes & Yes & Yes \\
\hline Physician Fixed Effect & Yes & Yes & Yes & Yes \\
\hline Time Fixed Effects & Yes & Yes & Yes & Yes \\
\hline Patient Controls & Yes & Yes & Yes & Yes \\
\hline Age & $\begin{array}{l}-0.0136 * * * \\
(0.000789)\end{array}$ & $\begin{array}{l}-0.0138 * * * \\
(0.000791)\end{array}$ & $\begin{array}{l}-0.0138 * * * \\
(0.000791)\end{array}$ & $\begin{array}{l}-0.0138 * * * \\
(0.000791)\end{array}$ \\
\hline Post Announcement & & $\begin{array}{l}-1.003 * * * \\
(0.0387)\end{array}$ & $\begin{array}{l}-1.017^{* * *} \\
(0.0389)\end{array}$ & $\begin{array}{l}-1.001 * * * \\
(0.0391)\end{array}$ \\
\hline Self-Experience & $\begin{array}{l}0.0429 * * * \\
(0.0128)\end{array}$ & $\begin{array}{l}0.0435^{* * *} \\
(0.0129)\end{array}$ & $\begin{array}{l}0.0410 * * * \\
(0.0129)\end{array}$ & $\begin{array}{l}0.00161 \\
(0.0155)\end{array}$ \\
\hline Self-Experience x Post & & & & $\begin{array}{l}0.0779 * * * \\
(0.0168)\end{array}$ \\
\hline Peer Experience & $\begin{array}{l}0.0855^{* * *} \\
(0.0146)\end{array}$ & $\begin{array}{l}0.0861 * * * \\
(0.0147)\end{array}$ & $\begin{array}{l}0.0886^{* * *} \\
(0.0147)\end{array}$ & $\begin{array}{l}0.0832 * * * \\
(0.0170)\end{array}$ \\
\hline Peer Experience $x$ Post & & & & $\begin{array}{l}0.0170 \\
(0.0161)\end{array}$ \\
\hline Self $x$ Peer Experience & $\begin{array}{l}-0.0220 * * * \\
(0.00838)\end{array}$ & $\begin{array}{l}-0.0218^{* * *} \\
(0.00839)\end{array}$ & $\begin{array}{l}-0.0507^{* * *} \\
(0.0110)\end{array}$ & $\begin{array}{l}-0.0423^{* * *} \\
(0.0113)\end{array}$ \\
\hline Self $x$ Peer $x$ Post & & & $\begin{array}{l}0.0496 * * * \\
(0.0126)\end{array}$ & $\begin{array}{l}0.0269 * \\
(0.0140)\end{array}$ \\
\hline _cons & $\begin{array}{l}0.854 * * * \\
(0.223)\end{array}$ & $\begin{array}{l}1.935^{* * *} \\
(0.227)\end{array}$ & $\begin{array}{l}1.947^{* * *} \\
(0.227)\end{array}$ & $\begin{array}{l}1.923 * * * \\
(0.228)\end{array}$ \\
\hline $\mathrm{AIC}$ & $143,819.3$ & $143,143.4$ & $143,129.8$ & $143,106.2$ \\
\hline Number of observations & 146,998 & 146,998 & 146,998 & 146,998 \\
\hline
\end{tabular}

note: ${ }^{* \star *} p<0.01,{ }^{\star \star} p<0.05,{ }^{*} p<0.1$

Table 6. Descriptive statistics of the variables captured in Study 2 by condition

\begin{tabular}{lcc}
\hline & $\begin{array}{c}\text { High perceived expertise } \\
\text { (i.e., Easy-task condition) }\end{array}$ & $\begin{array}{c}\text { Low perceived expertise } \\
\text { (i.e., Difficult-task } \\
\text { condition) }\end{array}$ \\
\cline { 2 - 3 } Perceived performance on the quiz & $4.94(1.01)$ & $3.16(1.50)$ \\
Perceived expertise & $4.75(1.11)$ & $3.51(1.39)$ \\
Escalation of commitment & $5.89(2.72)$ & $5.06(2.55)$ \\
\hline
\end{tabular}

